\title{
Charts and Tables
}

\section{CHARTS}

I. Organization of American States . . . . . . 303

II. Pan American Union .

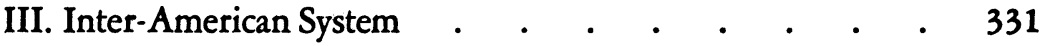

IV. Inter-American Defense Board . . . . . . 332

\section{TABLES}

1. Distribution of United States Assistance to Latin America by Program, July 1, 1940-June 30,1945 . . . . 242

2. Total Amount of United States Assistance, Net of Reciprocal Assistance and Repayments, to Latin America, July 1, 1945-

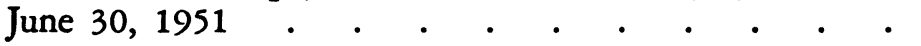

3. Value of United States Direct Investments in Latin America, by Industry, $1936-58$.

4. United States Program in Latin America, 1943-60 Technical Cooperation and Closely Related Activities . . 368

5. United Nations Expanded Program for Technical Assistance

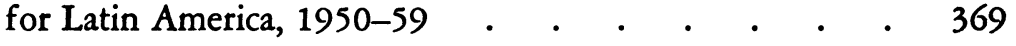

6. United States Assistance to Latin America,

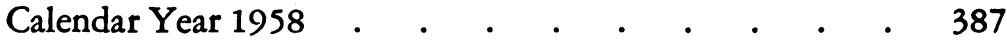
MAP

Collective Defense Arrangements . . . . facing page 2 
THIS PAGE INTENTIONALLY LEFT BLANK 


\section{The United States and \\ Inter-American Security 1889-1960}


THIS PAGE INTENTIONALLY LEFT BLANK 